\title{
Estimating the Outdoor Recreational Value of Lavizan Jungle Park of Tehran Using Contingent Valuation Method (CV)
}

\author{
Azam Abedini' ${ }^{1}$ Mohamad Hosein Mohamadi $^{2}$, Majid Kholuzini Sharahi ${ }^{3}$ \\ ${ }^{1}$ Economic Department, Tehran University, Tehran, Iran \\ ${ }^{2}$ Economic Department, Shahid Ashrafi Esfahani University, Isfahan, Iran \\ ${ }^{3}$ Economic Department, Allame Tabatab'i University, Tehran, Iran \\ Email: *mh.mohamadi1986@yahoo.com
}

Received 16 February 2016; accepted 16 April 2016; published 19 April 2016

Copyright (C) 2016 by authors and Scientific Research Publishing Inc.

This work is licensed under the Creative Commons Attribution International License (CC BY). http://creativecommons.org/licenses/by/4.0/

(c) () Op

\begin{abstract}
Natural resources and its condition have always had a key role in economic and social developments of different societies around the world and these resources are considered as natural capital and bankroll of economic growth and development for every country. In the present study, we have evaluated the outdoor recreational value of Lavizan Jungle Park of Tehran and its visitors' willingness to pay per visit (WTP) by using Contingent Valuation method (CV) and two-dimensional choice questionnaires. We used 125 questionnaires and logit model in order to evaluate the WTP. The purpose of this study is to measure individuals' willingness to pay for visiting and preserving the environment of Lavizan Park as well as indicating the relationship between influential factors on their WTP. Estimating the value of natural resources is very important in making environmental preservation policies because preserving these natural attractions, as a part of ecotourism, is highly important. JEL Classification: Q29, Q51, C25.
\end{abstract}

\section{Keywords}

Environment, Contingent Valuation (CV), Willingness to Pay, Logit Model

\section{Introduction}

The environment is the most important life factor of human beings but it has never been fully appreciated so that one of the main issues for governments in the $21^{\text {st }}$ century is environmental crisis. The misconception concern-

\footnotetext{
"Corresponding author.
}

How to cite this paper: Abedini, A., Mohamadi, M.H. and Sharahi, M.K. (2016) Estimating the Outdoor Recreational Value of Lavizan Jungle Park of Tehran Using Contingent Valuation Method (CV). Open Journal of Ecology, 6, $225-234$. 
ing services provided by ecosystems is a serious risk for the society. Therefore, adopting correct methods for the ecological management of natural resources based on sustainable development is necessary and it is essential to be aware of the functions of ecosystems and direct and indirect use of their services and products. Services and products of ecosystems are mostly of great value; however, they are rarely traded on the market. In addition, due to lack of possibility of quantitative and accurate calculations, they are being neglected in macro politics and macro-decision making. Quantifying such benefit in order to clarify the significance of these resources is impossible in practice. However, globally, they make effort to include the value of these resources in national accounts by using different economic theories [1]. Although these efforts are made based on estimations not the actual value of these resources, they can be very effective in preserving and protecting these resources.

\subsection{Theoretical Pricing Model}

The valuation of non-market functions and services of environment is important due to many reasons such as: Environmental and ecological knowledge and understanding by human beings, presenting the environmental issues to authorities and decision makers, providing a link between economic policies and incomes from nature, assessing the role and importance of natural resources in supporting the welfare of human beings and sustainable development, modifying national audits such as GDP and preventing the destruction and indiscriminate use of natural resources [2]-[4].

Nowadays, sustainable development, protection and improvement of the environment, proper use of natural resources and gaining multilateral recreational, educational and research profit from the natural conditions of environment are subjects that affect economic growth and social welfare worldwide.

Jungles are one of the most important natural resources of economic growth in many developing countries. In our country, jungles have played an important role in the socio-economic development as one of the infrastructures of development as well by providing products and services which are used either directly (wood, nontimber products and recreational services) or indirectly (producing oxygen, absorbing carbon-dioxide, preventing soil erosion and preserving and refining water).Consumer goods and services (direct or indirect) form the use value of jungles [5]. The other part of the value of jungles is related to their non-use value. This non-use value is related to the sums that people are willing to pay in order to conserve the environment. Hence, it is called conservation value as well [5].

Non-use value or conservation value includes existence value, heritage value and choice value. The existence value refers to the intrinsic value of a resource, and people value and its existence even if they never see or use it. Heritage value or future-generation value refers to the utility resulted from the awareness and knowledge of people regarding preserving natural resources for future generations. The choice value is an index of the degree of people's preference for preserving a natural resource against possible use in future. The value that people consider for visiting and using recreational areas belongs to these places and people can show it by the amount of money they are willing to pay. The difference in people's willingness to pay comes from demographical, economic, social, and other related factors. According to Ajzen Model [6], behavioral variables such as willingness to pay are a function of attitudes influenced by individuals' behavioral experiences. Knetsch [7] showed that the demand for natural attractions with unique sceneries and remarkable recreational facilities is inelastic to price. Therefore, existence value and choice value are defined as the amount of WTP to conserve the resource for future generations and to preserve it for possible use in future, respectively.

\subsection{Contingent Valuation Method}

Maximum willingness to pay (MWTP) for non-market goods such as improving the environment's quality, wildlife and jungles indicates the economic value of those resources [8]. In recent years, the contingent valuation method has been accepted by economists and politicians in order to estimate this value as well as other economic values [9].

Various studies show that CV method is the only method for conservation value of jungle resources. This method tries to determine the WTP under the scenario of a hypothetical market [10]. The CV method was first suggested by Ciriacy-Wantrap in 1947 but Davis put this method in practice for the first time in 1963 [11].

In this method, a questionnaire is used to directly ask people about the amount they are willing to pay for using or preserving an environmental product. Different steps must be taken in order to implement the contingent valuation. The first step is to determine the society that is affected by having or lack of access to the product. 
The study population is usually one of the social units (individuals and households). After determining the society, its sample is chosen. In the next step, a questionnaire is designed and the data is collected from the sample. The product must be described meticulously and in detail so that the respondents know its exact features. In other words, the respondents should know what they will receive in return of the amount of money they are willing to pay [9].

In the next part of the questionnaire, the method of payment is introduced so that if the respondent is willing to pay an amount, he knows how to pay it. To explain it simpler, the method of payment represents the system and mechanism under which sums of money are transferred [12]. The common payment methods in the contingent valuation method include entrance fee (paying an entrance fee to use the park), tax (such as increasing the income tax in order to protect jungles), donations to a certain institute (for example, people express their WTP by paying a membership fee to an NGO whose job is to protect environmental quality), and higher prices (for example, increasing the entrance fee) [9]. Lee and Mjelde [13] believe that the tax method has superiority over the donation method because the respondents feel that they have to pay them. However, if the condition of a society is so that people have less confidence in the tax system, using this method might result in people's objections and refusal to respond [14].

The last part of the questionnaire is the introduction of the method for extracting the MWTP of respondents. The methods of extraction are divided into two groups of continuous methods and discrete methods [9]. In continuous methods, the MWTP of respondent takes continuous figures. Open-ended payment card method and suggestion game method are examples of continuous methods. On the other hand, in discrete methods, the respondent is offered a price and is asked to provide a positive or negative answer to the offer. Therefore, in this method, the amounts of WTP are discrete. This group includes dichotomous choice methods (one-dimensional and two-dimensional), multiple choice and multidimensional choice [12].

There is a significant difference between the amounts of WTP earned from continuous and discrete extraction methods [15] so that several studies, after comparing the results of continuous and discrete methods, concluded that the amounts of WTP estimated from discrete methods are more than those of continuous methods [16]-[18].

Kaley and Turner [17] concluded that the WTP estimated from dichotomous-choice method was 1.5 to 2.4 times larger compared to the WTP estimated from open-ended method for public goods. However, the amounts of WTP gained from these two methods for private goods are not different. They argue that the reason for this equality is because the private good is known to the respondents. Kristrom [16] in a study to estimate the conservation value of a jungle area indicated that people express higher amounts of WTP in dichotomous-choice method compared to open-ended method.

The dichotomous-choice method (DC) was first presented by Heberlein and Bishop in 1979 [19]. In this method, respondents choose one offer out of a certain number of preset offers. Respondents give a "yes" or "no" answer to your offer in a hypothetical market. Hannemannin [20] modified the dichotomous choice method which resulted in double-bounded dichotomous choice (DDC) method. This method requires us to choose an offer higher than the first offer so that the higher offer depends on the yes or no answer or the reaction of the respondent.

The problem with dichotomous questionnaires in studying CV is that they include one dependent variable that requires a qualitative choice model. Logit and Probit models are usually used for qualitative choice methods [21].

In the present study, double-bounded dichotomous choice questionnaires have been used in order to estimate the visitors' WTP. The questionnaire has two parts which the first part includes socio-economic status of people so that it asks about the job, age, marital status, income and other characteristics of people. The second part is concerned with their willingness to pay. In this part, we offer three prices gained by using the Gauss software. In the first question, we have presented the first offer of 10,000 Rials, which is the mid price, by this means: Lavizan Park has provided you an opportunity for leisure and recreation; considering the park's conditions and its costs of care, as a visitor, are you willing to pay 10,000 Rials as an entrance fee? If the answer is negative, the lower offer (7000 Rials) is presented and if the answer is positive, the higher offer (15,000 Rials) is presented. The visitors may give positive or negative answers. In this study, we used Cochran formula and random sampling method in order to estimate the required number of samples. The required number of samples was obtained based on the analysis of the mean and variance of the statistical population gained from filling 30 questionnaires. Therefore, 125 questionnaires were filled. We excluded 19 questionnaires because they were either incomplete or the questions were not totally understood by the respondents. The analysis was carried out for 106 
questionnaires which were completed in the spring and summer of 1391 (2012).

\section{Material and Methods}

To determine the method for estimating WTP, we assume that the person will accept the entrance fee offered on the following condition so that he will maximize his utility [22]. The utility that the individual gains from using environmental resources is more than the state that he does not use environmental resources.

$$
U(1, Y-A ; S)+\varepsilon_{1} \geq U(0, Y ; S)+\varepsilon_{0} .
$$

$U$ represents the indirect utility that the person gains. $Y$ and $A$ stand for income and the offered price, respectively and $S$ is the other random variables with the mean of zero that are equally and independently distributed. Zero means that the person does not visit the jungle park and 1 means that he visits the park. $\varepsilon_{0}$ and $\varepsilon_{1}$ are random variables with the mean of zero which are equally and independently distributed.

$\Delta u$ can be described as the Equation (2):

$$
U(1, Y-A ; S)+\varepsilon_{1} \geq U(0, Y ; S)+\varepsilon_{0} .
$$

The probability $\left(P_{i}\right)$ that he will accept the offer $(A)$ is described as the following equation based on logit model:

$$
P_{i}=F_{\eta}(\Delta U)=\frac{1}{1+\exp (-\Delta U)}=\frac{1}{1+\exp \{-(\alpha-\beta A+\gamma Y+\theta S)\}} .
$$

$F_{\eta}(\Delta U)$ Isis the cumulative distribution function with a standard logistic difference and includes some of the socio-economic variables of this study. $Y$ and $A$ are designated as income and the offered price, respectively and $S$ is the other socio-economic characteristics influenced by individual preferences. $\theta, \gamma$ and $\beta$ are the estimated coefficients which are expected to be $\beta \leq 0, \gamma>0$ and $\theta>0$.

The parameters of logit model are estimated by using the maximum likelihood method which is the only technique to estimate logit models. Subsequently, the expected WTP is calculated using the numerical integration over the domain of zero and maximum offer (A) as follows:

$$
\mathrm{E}(\mathrm{WTP})=\int_{0}^{M A X \cdot A} F_{\eta}(\Delta U) \mathrm{d} A=\int_{0}^{M A X \cdot A}\left(\frac{1}{1+\exp \left\{-\left(\alpha^{*}+\beta A\right)\right\}}\right) \mathrm{d} A .
$$

(WTP) is the expected amount of WTP and $\alpha^{*}$ is the adjusted y-intercept that has been added to the main y-intercept sentence $(\alpha)$ by the socio-economic sentence $\alpha^{*}=\alpha+\gamma Y+\theta S$ [23]. Logit models can be estimated in logarithmic or linear forms.

\subsection{Introducing Lavizan Park}

Lavizan Jungle Park is one of Tehran's jungle parks with an area of 1001 hectares. From north it is limited to Ghochak district and from south it is limited to Shams Abad town. Lavizan village is located in the western part of the park. The park is distanced 13 kilometers from the downtown and is the largest green area of Tehran. It is a convenient place for families to spend leisure time. Due to its natural situation and the road going through it, the park creates scenic views and enjoyable moments. Useful and desirable function of urban parks alongside having facilities and green area depends on an appropriate management structure. Therefore, by employing a consulting firm in 1385 (2006), the management of municipality of area 4 of Tehran decided to prepare the plan of "The Productivity Management of Lavizan Jungle Park" (as one of the most important and the largest green areas of Tehran and a valuable opportunity) in order to prevent destructive, unstable and violating methods to the park based on the ecological and environmental capabilities and modern urban needs.

On June 25, 2011, the construction of the largest birds park of the country in Lavizan Jungle Park started with the presence of M.B. Ghalibaf the mayor of Tehran. Reportedly, this recreational and tourist project is unique in the Middle East and 22 hectares of Lavizan Jungle Park has been allocated to it. This project is consisted of 2 phases. The first phasecame into operation on April 28, 2013 as the Pasture Area and the second phase will be exploited in the next step. The birds park is located in the eastern part of the park and is limited to Sh. Babaee Highway from north, Esteghlal Avenue and Golestan Town from south, Kohestan Avenue from west and Omid 
Town from east. In the area allotted to the birds park, due to the plantation of desirable species of trees for birds, the green area is not destroyed and yet reinforced in the terms of diversity and structure. It has been arranged to plant over 30,000 different trees and bushes and to use drip irrigation in order to improve the productivity of resources. There are six thousand birds in this tourist area and there is a children playground with modern rope games next to it which can create a happy and enjoyable atmosphere. In this set, different kinds of pasture birds including ostriches, geese, ducks, flamingos, water birds, peacocks, vultures, falcons, owls, eagles, different kinds of parrots and pigeons are caged.

\subsection{Review of Literature}

Many studies have been done on estimating the amount of profits gained from visiting recreational areas using contingent valuation method. For example, Chopra [24] stated that the existence value of tropical jungle is equal to $91 \%$ of use value. In a study done by Echeverria and et al. [25], the contingent valuation method was used in order to estimate the existence value of Costa Rican jungles which was annually 238 dollars per hectare. Costanza and et al. [26] studied the total value of environmental and ecological services of 17 different ecosystems around the world and reported that in order to calculate the existence value of the jungle, the mean WTP is collected from the questionnaires and then is multiplied by the total number of the respondents. Tomas and Christopher [27] using CV method found out that in America people were willing to pay between $\$ 0$ to $\$ 325$ a year in order to protect groundwater from chemical pollutants. Kramer and Mercer [28] studied the existence and conservation value of jungles in America. Loomis Gonzales-Cabon [29] also used CV method and WTP in order to estimate the existence value of jungles. White and Lovett [30] estimated the conservation value of North York Park, England using CV method.

Lee and Han [10], using CV method, estimated that the outdoor recreational value for 5 Korean national parks was an average of $\$ 10.45$ a year for each household. Amigues and et al. [31] estimated the preservation value of Garonne river bank ecosystem in France, using CV method with Tobit linear model, semi-logarithmic model and Heckman two-stage model at 66-67-13-133, respectively. Salazar and Mendez [32] estimated the non-market value of the City Park of Valencia, Spain at 11,942 pesos a year. Leong and et al. [33] studied the preservation value of mountainous jungles of Malaysia and the results revealed that the preservation value for each respondent (was in the range of 20 to 27 units.). Leinhoop and Mac Millan [34] estimated the value of desert areas of Iceland at 16 and 143 Euros a year. Sattout and et al. [35] estimated the recreational value of cedar jungles of Lebanon at \$42 and \$43 per family a year. Reynisdottir and et al. [36], using CV method, estimated the WTP for (Schoffel National Park and Glencar Waterfall) in Ireland at 508 and 333 million kroner, respectively. The outdoor recreational value of Madagascar Jungles was estimated \$360 to \$468 using travel cost method [37]. The value of jungles of Montana State of America, according to contingent valuation method, was $\$ 108$ for each travel and for eastern jungles of America, this amount was $\$ 10.43$ a year for each household [38]. Pajiola [39], using CV method, estimated that locals and tourists were willing to pay $\$ 170$ and $\$ 70$, respectively in order to repair the Roman Palace in the ancient city of Split, Croatia. Togrido, et al. [40] estimated visitors' WTP for Alonnisos Marine Park, Greece 120 and 30 BWP for locals and tourists, respectively. Whitehead and Finney [41] valued the North Carolina Coast, US, using CV method. The mean WTP for each visitor was \$36 and the annual benefit gained from historical shipwreck park was estimated at 1.75 million dollars (this coast has about 5000 shipwrecks).

In addition, in Iran, several studies have been done on estimating preservation and recreational values of parks and resorts which are briefly presented in this study. For the first time, Bakhshaei [42] estimated the outdoor recreational value of Si Sangan Park using TC method at 8960 Rials a year. Mirzaei [43] estimated the annual recreational value of Palang Dareh Area of Qom at 83,395 Rials using TC method. Khorshiddoust [44], using CV method, estimated the WTP of people of Tabriz City for preserving urban environment and reducing the pollutions at 41,140 Rials a month. Amir Nejad and et al. [45], using the CV method, estimated the outdoor recreational value of Golestan National park at about 18 billion Rials a year. Amir Nejad and Khalilian [46] studied the preservation and recreational values of Si Sangan Park. The results revealed that $81.7 \%$ of people were willing to pay an amount of money in order to preserve the park and the mean WTP was 6365 Rials. Khodaverdi Zadeh and et al. [47] estimated the mean WTP and the annual recreational value of Kandovan Village at 3905 and 1,171,500 Rials, respectively using CV method. Emami Meybodi and Ghazi [21] estimated the annual recreational value of Saee Park of Tehran at about 2.7 billion Rials. Amir Nejad and Rafie [48] estimated the WTP for gaining utility from recreational use of Abbas Abad recreational area, Behshahr City at 2200 Rials per per- 
son each visit. The annual mean WTP for visiting Abbas Abad Jungle was 95,040 Rials each household. Molaie [49] estimated the preservation value and recreational value of Arasbaran Jungles respectively at 1111.18 and 1.075 billion Rials.

\section{Results and Discussion}

To estimate the value of the park, at the beginning of the questionnaire, we mentioned that those respondents are required who are able to make financial decisions independently. In this questionnaire, various questions have been asked which are in the forms of real and dummy variables. The dummy variables include: gender, job, education, membership in environmentalist organizations, marital status, driving personal car to the park and type of housing (private or rental). The real variables include: age, number of household members, monthly income, the estimated cost of visiting the park, time distance between the house and park, the average time spent in the park per visit, number of annual visits of the park, park's quality (choosing a number between 0 - 100) and park's facilities (choosing a number between 0 - 100).

Table 1 shows the occupational distribution of statistical society. 56.6\% of visitors are self-employed or employees. This shows that occupational status and of course the people's income are the main items for people's visiting the social areas.

Table 2 shows Lavizan park visitors' level of education. 61.32\% of visitors are having Associate Degree or above. Based on the growth in education and educated people in Iran, we can expect that the number of park visitors will increase in the coming years.

Table 3 and Table 4 show the statistical distribution of facilities and quality of the park from the visitors' point of view. Since $80.19 \%$ of visitors scored the park facilities and $67.92 \%$ scored park quality below 60 from 100 , we can conclude that most of the visitors are not satisfied of the park atmosphere and we can encourage more people for visiting and using the available resources by increasing the facilities and quality of the park atmosphere.

The respondents of this study were 61 men (57.55\%) and 45 women (42.45\%). forty five persons (42.45\%) were willing to pay an entrance fee to use the park and 61 persons (57.55\%) were not willing to pay an entrance fee.

Twenty seven persons accepted the 10,000-rial entrance fee. Two persons were willing to pay 15,000 Rials after having accepted the 10,000-rial offer. Sixteen persons did not accept the 1000-rial offer; however, they accepted to pay 7000 Rials as an entrance fee. The results of logit model are shown in Table 5 after the elimination of meaningless variables.

Table 1. Distribution of visitors' jobs.

\begin{tabular}{ccccccccc}
\hline & Employee & Teacher & Self-employed & Student & Housewife/husband & Worker & Retire & Total \\
\hline Number & 19 & 3 & 41 & 25 & 15 & 0 & 3 & 106 \\
Percentage & 17.92 & 2.83 & 38.68 & 23.58 & 14.15 & 0 & 2.83 & 100 \\
\hline
\end{tabular}

Table 2. Distribution of visitors' education.

\begin{tabular}{ccccccc}
\hline & $\mathrm{PhD}$ & M.A/M.S & B.A/B.S & Associate degree & Diploma/undergraduate & Total \\
\hline Number & 3 & 9 & 33 & 20 & 41 & 106 \\
Percentage & 2.83 & 8.49 & 31.13 & 18.87 & 38.68 & 100 \\
\hline
\end{tabular}

Table 3. Distribution of park’s facilities.

\begin{tabular}{cccccccc}
\hline & $0-20$ & $21-40$ & $41-60$ & $61-80$ & $81-100$ & 3 \\
Number & 34 & 26 & 25 & 18 & 106 & 16.98 & 2.83 \\
Percentage & 32.08 & 24.52 & 23.59 & 100 \\
\hline
\end{tabular}

Table 4. Distribution of park's quality.

\begin{tabular}{cccccccc}
\hline & $0-20$ & $21-40$ & $41-60$ & $61-80$ & $81-100$ & 9 \\
Number & 17 & 21 & 34 & 25 & 106 & 9.49 & 100 \\
Percentage & 16.04 & 19.81 & 32.07 & 23.59 & 8.49 \\
\hline
\end{tabular}


Table 5. The results of logit model for Lavizan Park, after the elimination of meaningless variables.

\begin{tabular}{cccc}
\hline Variable & Coefficient & Statistical value of t & Meaningfulness \\
Constant factor & -9.01591 & -3.817486 & 0.0001 \\
Age & -0.130756 & -1.693079 & 0.0904 \\
Number of household members & -0.994341 & -0.808766 & 0.0705 \\
Facilities & 0.039147 & 1.864374 & 0.0623 \\
Income & 0.008118 & 2.894571 & 0.0038 \\
Marital status & -2.147412 & -2.110192 & 0.0348 \\
Jime distance between the house and park & 0.884986 & 2.151717 & 0.0314 \\
Recommendation & -0.539834 & -2.084055 & 0.0372 \\
Mc Fadden R-squared $=0.404490$ & -0.001174 & -4.532149 & 0.0000 \\
LR statistic: 62.06367 prob(LR statistic) $=0.000000$ & & & \\
Log likelihood $=-45.68663$ & & & \\
\hline
\end{tabular}

Reviewing the coefficients shows that the entrance fee offer is at $1 \%$ significance level and it is negative which means the more the entrance fee increases, the less its WTP will be. The coefficient of income variable is at $1 \%$ significance level and it is positive, which means the more is the income, the more is the possibility of willingness to pay an entrance fee.

The marital status variable is at 5\% significance level and is negative, which means the possibility of accepting the entrance fee by the married individual is less. The independent variable of time distance between the house and park is $5 \%$ significant and is positive. The independent variable of job is $5 \%$ significant and is positive and shows that the possibility of accepting the entrance fee by employees and teachers is higher.

The independent variables of age and number of household members are $10 \%$ significant and have negative effect and the independent variable of park facilities is $10 \%$ significant and has positive effect.

\section{Calculating the WTP and the Total Annual Outdoor Recreational Value of the Park}

There are three methods for calculating the amount of WTP: the first method is the mean WTP, in which the numerical integration over the domain of zero to infinity is used in order to calculate the expected amount of WTP $\{\mathrm{E}(\mathrm{WTP})\}$. The second method is the mean of total WTP, which they use the numerical integration over the domain of $-\infty$ to $+\infty$ to calculate E (WTP). The third method is the mean of partial WTP, in which the numerical integration over the domain of zero and maximum offer (A) is used in order to calculate E (WTP). Among these methods, the third one is the best because it retains the consistency and agreement of limitations with the theory of statistical efficiency as well as integrability (Amir Nejad et al. [45]).

$$
\begin{aligned}
& \mathrm{E}(\mathrm{WTP})=\int_{0}^{\text {MAX.A }} F_{\eta}(\Delta U) \mathrm{d} A=\int_{0}^{\text {MAX.A }}\left(\frac{1}{1+\exp \left\{-\left(\alpha^{*}+\beta A\right)\right\}}\right) \mathrm{d} A \\
& \mathrm{E}(\mathrm{WTP})=\int_{0}^{15000} \frac{1}{1+\exp \{-(4.0485-0.0011 A)\}} \mathrm{d} A=3696.1764
\end{aligned}
$$

Therefore, an amount of 3696.1764 is obtained as the mean price for each visit of the park.

In an interview that we had with the park manager, he described the number of visits to the park as follows. The average number of visits on weekdays was 6000; it was 25,000 on weekends and it was 250,000 visits on national Nature Day (April $2^{\text {nd }}$ ). Therefore, the number of total annual visits is 1,893,000 and the total outdoor recreational value is calculated through the following equation:

Total value of park $=$ the mean WTP $\times$ the number of total annual visits

Total value of park $=3696.1764 \times 1,893,000=6,996,861,925$

Therefore, the total outdoor recreational value of Lavizan Park is 6,996,861,925. 


\section{Conclusion}

In this study, we estimated the outdoor recreational value of Lavizan Park of Tehran using the CV method, the WTP and dichotomous-choice questionnaires. In this study, the payment tool pays an amount of money as an entrance fee because people can express their selection criteria based on monetary measures within a hypothetical market. In this study, the mean WTP was 3696.1764 Rials and its maximum amount was 15,000 Rials. The total outdoor recreational value of the park was estimated at 6,996,861,925 Rials during a year. The results reveal that the amount of entrance fee and income are the most influential factors on the WTP and they are at $1 \%$ significance level. The variables of marital status, time distance between the house and park and job are at 5\% significance level and the variables of age, the number of household members and park facilities are at $10 \%$ significance level. In a metropolis such as Tehran, which pollution and lack of green areas are the main problems, proper planning for increasing health, recreational facilities and safety features can lead to higher use of jungle parks, which can be an effective step in increasing citizens’ psychological comfort and peace.

\section{References}

[1] Hooshmandi, S. (2011) An Estimation of Economic-Recreational Value of Pardisan Forest Park of Tehran, by Using the Contingent Valuation Method. M.A. Thesis.

[2] Vaze, P. (1998) System of Environment and Economic Accounting (SEEA). Chap. 13, United Nations Statistics Division, London.

[3] Ashim, G.B. (2000) Green national Accounting: Why and How? Environment and Development Economics, 5, 25-48. http://dx.doi.org/10.1017/S1355770X00000036

[4] Guo, Z., Xiao, X. Gan, Y. and Zheng, Y. (2001) Ecosystem Functions, Services and Their Values a Case Study in Xingshan Country of China. Ecological Economics, 38, 141-145. http://dx.doi.org/10.1016/S0921-8009(01)00154-9

[5] Pearce, D.W. and Pearce, C.G.T. (2001) The Value of Forest Ecosystem.

[6] Ajzen, I., Brown, T.C. and Rosenthal, L.H. (1996) Information Bias in Contingent Valuation: Effects of Personal Relevance, Quality of Information, and Motivational Orientation. Journal of Environmental Economics and Management, 30, 43-57. http://dx.doi.org/10.1006/jeem.1996.0004

[7] Knesth, J.L. and Sinden, J.A. (1984) Willingness to Pay and Compensation Demanded: Experimental Evidence of an Unexpected Disparity in Measures of Values. Quarterly Journal of Economics, 99, 570-521.

[8] Kealy, J.M. and Turner, R.W. (1993) A Test of the Equality of Close-Ended and Open-Ended Contingent Valuations. American Journal of Agricultural Economics, 75, 321-331. http://dx.doi.org/10.2307/1242916

[9] Mitchell, R.C. and Carson, R.T. (1989) Using Surveys to Value Public Goods: The Contingent Valuation Method. Resources for the Future, Washington DC.

[10] Lee, C. and Han, S.Y. (2002) Estimating the Use and Preservation Values of National Parks Tourism Resources Using a Contingent Valuation Method. Tourism Management, 23, 531-540.

[11] Venkatachalam, L. (2003) The Contingent Valuation Method: A Review. Environmental Impact Assessment Review, 24, 83-124.

[12] Tkac, J.M. (2002) Estimating Willingness to Pay for the Preservation of the Alfred Bog Wetland in Ontario: A Multiple Bounded Discrete Choice Approach. M.sc. Thesis, Department of Agricultural Economics, Macdonald Campus of McGill University, Montreal.

[13] Lee, C. and Mjelde, J.W. (2007) Valuation of Ecotourism Resources Using a Contingent Valuation Method: The Case of the Korean DMZ. Ecological Economics, 63, 511-520. http://dx.doi.org/10.1016/j.ecolecon.2006.12.011

[14] Stevens, T.H., Echeverria, J., Glass, R.J., Hage, T. and More, T.A. (1991) Measuring the Existence Value of Wildlife: What Do CVM Estimates Really Show? Land Economics, 67, 390-400. http://dx.doi.org/10.2307/3146546

[15] Brown, T., Champ, P., Bishop, R. and McCollum, D. (1996) Which Response Format Reveals the Truth about Donation to a Public Good? Land Economics, 72, 152-166. http://dx.doi.org/10.2307/3146963

[16] Kristrom, B. (1993) Comparing Continuous and Discrete Valuation Questions. Environmental and Resource Economics, 3, 63-71. http://dx.doi.org/10.1007/BF00338320

[17] Kealy, J.M. and Turner, R.M. (1993) A Test of the Equality of Close-Ended and Open-Ended Contingent Valuations. American Journal of Agricultural Economics, 75, 321-331. http://dx.doi.org/10.2307/1242916

[18] McFadden, D. (1994) Contingent Valuation and Social Choice. American Journal of Agricultural Economics, 7, 689708. http://dx.doi.org/10.2307/1243732

[19] Bishop, R. and Heberlein, T.A. (1979) Measuring Values of Extra-Market Goods: Are Indirect Measure Biased? 
American Journal of Agricultural Economics, 61, 926-930. http://dx.doi.org/10.2307/3180348

[20] Hannemann, W.M. (1984) Welfare Evaluations in Contingent Valuation Experiments with Discrete Responses. American Journal of Agricultural Economics, 71, 332-341. http://dx.doi.org/10.2307/1240800

[21] Emami Meibodi, A. and Ghazi, M. (1387) Estimate the Recreational Value in Tehran Saee Park Using Contingent Valuation. Journal of Economic Studies, 36, 187-202.

[22] John-Adjaye, A. and Tapsuwan, S. (2008) A Contingent Valuation Study of Scuba Diving Benefits: Case Study in Mu KO Similan Marine National Park, Thailand. Tourism Management, 29, 1122-1130. http://dx.doi.org/10.1016/j.tourman.2008.02.005

[23] Haneley, N. (1997) Environmental Economics in Theory and Practice. Macmillan Press Ltd., London, 384-403. http://dx.doi.org/10.1007/978-1-349-24851-3

[24] Chopra, K. (1993) The Value of Non-Timber Forest Products: Estimation for Tropical Deciduous Forests in India. Economic Botany, 47, 251-257. http://dx.doi.org/10.1007/BF02862291

[25] Echeverria, J., Hanrahan, M. and Solorzan, R. (1995) Valuation of Non-Priced Amenities Provided by the Biological Resources within the Monterverde Cloud Forest Preserve, Costa Rica. Ecological Economics, 13, 43-52. http://dx.doi.org/10.1016/0921-8009(95)00054-D

[26] Costanza, R., d’Arge, R., de Grass, M., Hannon, B., Limburg, K., Naeem, S., O’Neill, R.V., Paruelo, J., Rakin, R.G., Sutton, P. and Vanden Belt, M. (1997) The Value of the World Ecosystem Services and Nature Capital. Nature, 387, 253-260. http://dx.doi.org/10.1038/387253a0

[27] Thomas, H. and Christopher, B. (1997) Conjoint an Analysis of Ground Water Protection Programs. American Journal of Agricultural Economics, 57, 188-198.

[28] Kramer, R.A. and Mercer, D.E. (1997) Valuing Global Environmental Goods: US Residents Willingness to Pay Protect Tropical Rain Forests. Land Economics, 73, 196-210. http://dx.doi.org/10.2307/3147282

[29] Loomis, J.B. and Gonzalez-Cabon, A. (1998) A Willingness to Pay Function for Protecting Acres of Spotted Owl Habitat from Fire. Ecological Economics, 25, 315-322. http://dx.doi.org/10.1016/S0921-8009(97)00044-X

[30] White, P.C.L. and Lovett, J.C. (1999) Public Preferences and Willingness to Pay for Nature Conservation in the North York Moors National Park, UK. Journal of Environmental Management, 55, 1-13. http://dx.doi.org/10.1006/jema.1998.0250

[31] Amigues, J., Boulatoff, C. and Desaigues, B. (2002) The Benefits and Costs of Riparian Analysis Habitat Preservation: A Willingness to Accept/Willingness to Pay Contingent Valuation Approach. Ecological Economics, 43, 17-31. http://dx.doi.org/10.1016/S0921-8009(02)00172-6

[32] Salazar, S. and Mendez, L. (2005) Estimating then On-Market Benefits of an Urban Park: Does Proximity Matter? Land Use Policy, 241, 296-305.

[33] Leong, P.C., Zakarian, M., Ghani, A.N.A. and Mohd, A. (2005) Contingent Valuation of a Malaysian High Land Forest: Non Market Benefits Accrued to Local Residents. Journal of Applied Science, 5, 916-919. http://dx.doi.org/10.3923/jas.2005.916.919

[34] Leinhoop, N. and MacMillan, D. (2007) Valuing Wilderness in Iceland: Estimation of WTA and WTP Using the Market Stall Approach to Contingent Valuation. Land Use Policy, 24, 289-295.

http://dx.doi.org/10.1016/j.landusepol.2005.07.001

[35] Sattout, E.J., Talhouk, S.N. and Caligari, P.D.S. (2007) Economic Value of Cedar Relics.

[36] Reynisdottir, M., Song, H. and Agrusa, J. (2008) Willingness to Pay Entrance Fees to Natural Attractions: An Icelandic Case Study. Tourism Management, 29, 1076-1083. http://dx.doi.org/10.1016/j.tourman.2008.02.016

[37] Maille, P. and Mendelsohn, R. (1991) Valuing Ecotourism in Madagascar. Yale School of Forestry, Mimeo, New Haven.

[38] Krieger, D.J. (2001) Economic Value of Forest Ecosystem Services: A Review. The Wilderness Society, Washington DC.

[39] Pagiola, S. (2001) Valuing the Benefits of Investments in Cultural Heritage: The Historic Core of Split. International Conference on Economic Valuation of Cultural Heritage, Cagliari, 19-20 October 2001. https://www.researchgate.net/publication/250917239

[40] Togridou, A., Hovardas, T. and Pantis, J.D. (2006) Determinantes of Visitors' Willingness to Pay for the National Marine Park of Zakynthos, Greece. Ecological Economics, 60, 308-319.

[41] Whitehead, J.C. and Finney, S. (2003) Willingness to Pay for Submerged Maritime Cultural Resources. Journal of Cultural Economics, 27, 231-240. http://dx.doi.org/10.1023/A:1026384602020

[42] Bakhshaei, A. (1353) Introduction of National Parks and Forests. Tehran University Press, Tehran. 
[43] Mirzaei, M. (1379) Vegetation and Ecological Value of Semidesert Area Southwest of Qom (the Panther Valley). Thesis Plant Sciences, Tarbiyat Modars University, Tehran.

[44] Khorshiddoust, A.M. (1384) Contingent Valuation in Estimating the Willingness to Pay for Environmental Conservation in Tabriz, Iran. Environmental Studies, 30, 12-21.

[45] Amir Nejad, H. (1385) Total Value of Forest Eco-System in Northern Iran, with an Emphasis on the Valuation of Environmental, Ecological and Conservation Value. PhD Thesis, Tarbiat Modaress University, Tehran.

[46] Amir Nejad, H., Khalilian, S. and Osare, M. (1385) Protective Value and Walk Park Sisangan Forest, Noshahr. People Using Willingness to Pay. Journal of Natural Resources and Construction, No. 72, 15-24.

[47] Khodaverdi Zadeh, M., Hayati, B. and Kavoosi, M. (1387) East Village Tourist Outing Kandovan Estimated Value Using Contingent Valuation. Environmental Sciences, 5, 43-52.

[48] Amirnejad, H. and Rafie, H. (1388) Economic Valuation of Environmental (Case Study of Forest Tourism Area of Abass Abad, Mazandaran Province). Agri-Sciences and Natural Resources, No. 3.

[49] Molaie, M., Yazdani, S. and Sharzehi, G. (2009) Estimating Preservation Value of Arasbaran Forest Ecosystem Using Contingent Valuation. Journal of Agricultural Economics, 3, 37-64. 